\title{
Orchidopexy in a Military Hospital
}

\author{
Major N B Corner \\ FRCS, RAMC
}

\author{
Major R J Bissett \\ $M B, C h B, R A M C$
}

Capt J B Hull

$M B, C h B, R A M C$

\section{Lt Col P Roberts \\ MBE, FRCS, RAMC}

British Military Hospital, Munster, BFPO 17

SUMMARY: A retrospective analysis of 53 consecutive cases of orchidopexy performed at the British Military Hospita苞 Munster between 1984 and 1988 showed that the average age of referral for orchidopexy was 4 years 7 months and tha $\mathbb{R}$ the average age at surgery for mal/un-descended testes was 5 years exactly. Sixty-four percent of all orchidopexies were్ carried out before the age of 5 years; 8 percent were carried out by the age of 2 years.

\section{Introduction}

A knowledge of the normal processes of formation and descent of the testis and its attachments is of help in understanding the abnormal.

The testis develops on the posterior abdominal wall, overlying the mesonephros. Distal to this a column of mesenchyme builds up, initially as a fold, connecting the testis to a gap in the developing abdominal muscles, the future inguinal canal. Differentiation of the body wall muscles and a little later the fasciae leaves the mesenchymatous gubernaculum running from testis to scrotum. Testicular descent requires not only the establishment of the gubernacular components and the presence of interstitial cells capable of androsteroid production, when stimulated by gonadotrophins, but also a free mesenchymatous pathway. Fibrous enchroachment on the mesenchyme may cause tethering of the testis if partial, or obstruction to its descent if complete. Descent is thought to be effected by a combination of the relative lack of growth of the gubernaculum compared with the rest of the body ${ }^{1.2}$, and an increase in intra-abdominal pressure, gently expelling the testes from the abdominal cavity into the scrotum following the path of the gubernaculum ${ }^{3}$. Completion of this normal process is necessary for normal testicular function ${ }^{4}$.

Maldescent of the testis may be classified using various terminologies. For the purpose of this paper a testis that has failed to complete its passage to the scrotum, but remains on the normal line of descent, is referred to as undescended. Any testis which spontaneously takes up a position away from the normal line of descent can be regarded as ectopic. Together they may be considered to be maldescended ${ }^{5}$. If an inguinal pouch testis can be coaxed into the scrotum it is tethered; if not, it is obstructed ${ }^{3}$.

Operation in early childhood is generally accep treatment for undescended and ectopic testes. Tespes which lie in the low scrotal position and which retræe readily to or toward the external inguinal ring proba do not require operation ${ }^{3}$, although there is soge evidence that maturation may not be normal in a te\$is described as "retractile". 6

A testis that has not reached the bottom of scrotum by the first six weeks of life (three months in $क$ premature infant) appears to remain permanently higher than its fellow. It is now accepted practice for orchidopexy to be carried out by the age of 2 years in order to allow for their normal development anc function?

The aim of our retrospective study was to discover whether orchidopexy in the military community is being carried out by an acceptable age?

\section{Patients and Method}

A retrospective study was undertaken of a orchidopexies carried out at the British Militar Hospital Munster in the 4 year period between Januarg 1984 and February 1988. Fifty-three cases wer? identified and studied. In all cases it was establisheథ when the patient was referred for surgery and whe surgery was undertaken. It was often not possible t $Q$ establish whether the condition was recorded at birth as the post-natal notes were unavailable in patients born is other hospitals. The date of the first referral letter was̄ often the first mention of the condition in the medicaP records. This suggests the possibility that the abnormats descent was not noticed, or indeed, not present at birth ${ }^{9} \mathrm{~N}$ 


\section{Results}

Of the 53 cases studied the average age of referral was 4 years 7 months. The youngest patients were referred for surgical opinion during the peri-natal period. The youngest patient operated upon was aged 1 month, the indication for surgery being a large congenital hernia. Fourteen patients had bilateral maldescent. Forty-seven percent of the maldescended testes were associated with herniae.

The average age at surgery was 5 years exactly. The delay from referral until surgery was acceptable in most cases, the median figure being 3 months. The mean delay was artificially inflated by two patients who were lost "in the system" and had their surgery delayed by 41 and 46 months respectively. One of these patients was a civilian whose parents had been reassured in the UK that his testes would drop on their own. Since moving to BAOR the patient had not attended for review and his condition was unknown to the military medical services. Surgery was undertaken promptly once his new general practitioner became aware of the situation.

Three other patients experienced lengthy delay in surgery once they had been referred. The intervals in these cases were 21, 22 and 23 months respectively. The delay was due to specialist clinicians, one paediatric and two surgical, waiting to see if spontaneous resolution would occur in patients with high "retractile" testes.

\section{Table 1}

\section{Age at referral and surgery for abnormal testicular descent}

\begin{tabular}{cccc}
\hline $\begin{array}{c}\text { Age in months } \\
\text { (years) }\end{array}$ & $\begin{array}{c}\text { No: } \\
\text { referred }\end{array}$ & $\begin{array}{c}\text { No; } \\
\text { at surgery }\end{array}$ \\
\hline $0-6$ & & 4 & 2 \\
$7-12$ & 3 & 0 \\
$13-18$ & 2 & 1 \\
$19-24$ & & 2 & 1 \\
$25-36$ & $(2)$ & & \\
$37-48$ & $(3)$ & 8 & 7 \\
$49-60$ & $(4)$ & 8 & 14 \\
$61-72$ & $(5)$ & 9 & 9 \\
$73-84$ & $(6)$ & 6 & 3 \\
$85-96$ & $(7)$ & 2 & 4 \\
$97-108$ & $(8)$ & 3 & 5 \\
$109-129$ & $(9)$ & 2 & 2 \\
$121+$ & $(10+)$ & 2 & 2 \\
& & 2 & 3 \\
& & - & - \\
& & 53 & 53 \\
\hline
\end{tabular}

\section{Discussion}

In the past it was generally accepted that 3 maldescended testes should be fixed in the scrotum by $\stackrel{\varnothing}{\complement}$ puberty and many advocated between the ages of 6 and $O$ 8 years $^{5}$.

There has been no universally accepted classification of maldescent and uncertainty in such cases as to $\overrightarrow{\overrightarrow{\mathrm{D}}}$ whether testicular abnormalities are the cause or effect of the abnormal descent. Discussion has inevitably been based on fragmentary evidence and Whitaker ${ }^{10}$ noted $\frac{\bar{\sigma}}{\bar{D}}$ the lack of a report correlating fertility with age at $\vec{\Phi}$

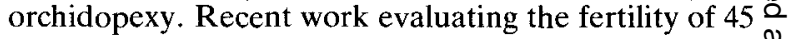
men after late spontaneous descent of previously $\stackrel{\omega}{\infty}$ maldescended testes found only $33 \%$ to have normal $\overrightarrow{0}$ fertility, as estimated from the results of total semen $\vec{\overrightarrow{ }}$ analysis ${ }^{11}$.

The association of testicular malignancy and maldescent of the testis is well established ${ }^{3}$. Some $10 \stackrel{2}{3}$ percent of all germinal cell tumours arise in maldescended testes, with the highest incidence $\vec{\omega}$ affecting intra-abdominal organs ${ }^{12}$.

If the testis are left at the higher temperature of the body long enough, normal maturation is severely $\dot{\infty}_{\infty}$ retarded. The scrotum and cremaster act as a thermo- 0 regulator, keeping the testis a degree or two cooler than normal body temperature, and it is generally accepted that the degeneration of seminiferous tubules 鬲 maldescent is at least partly, and in ectopic test mainly, due to their location in positions of high\& temperature. The maldescended testis shows retardation of growth of tubular diameter and reduction of spermatogonia content and, at puberty, failure spermatogenesis together with peritubular fibrosis ${ }^{3,4}$.

It has been noted that the higher the testis resides above the scrotum, the more dysgenetic the morphology is likely to $\mathrm{be}^{13}$. Mengel et al ${ }^{14}$ showed that degeneration $\stackrel{\varnothing}{\varnothing}$ could begin at 2 years. In a study of biopsies from $515 \overline{\bar{O}}$ maldescended and 237 unilaterally descended testes, the $\frac{0}{3}$ spermatagonia content (the number of spermatogonia in 50 tubules) started diminishing from 2 years of age. In no case was there complete loss of the germinal epithelium before the age of 2 .

Histological appearances can improve after orchidopexy. In a series of 29 bilateral orchidopexies done one at a time with an interval of at least a year, Kiesewetter, Shull and Fetterman ${ }^{4}$ took bilateral biopsies on each occasion. They used the following criteria in evaluating the histology: 1) number of tubules; 2) size of tubules; 3) degree of layering of $\mathrm{O}$ tubular cells; 4) amount of interstitial tissue; 5) presence or absence of interstitial (Leydig) cells; 6) presence or 옥 absence of spermatogonia; 7) state of germinal activity. $\rightarrow$ They found moderate to marked improvement in $52 \%$ 으․ following successful orchidopexy. Hecker and Hienz ${ }^{15} \bar{N}$ reported similar findings.

Fonkalsrud ${ }^{13}$ concluded that the maldescended testis $\widetilde{N}$ does not mature normally after the age of two years and 
may produce adverse effects on the contralateral descended testis, possibly by an auto-immune mechanism.

Functional, psychological and oncogenic considerations all point towards orchidopexy well before 5 years of age, and we consider that, based on evidence presented here, surgery should ideally be carried out before the second birthday. Even though fertility often follows bilateral orchidopexy in late childhood, in other patients irreversible degeneration may take place soon after 2 years of age ${ }^{14}$. Some testes may be inherently inferior, but it is impractical to confirm this, so correction should not be delayed ${ }^{16}$. This argument is further supported by the recent work of Bremholm Rasmussen ${ }^{11}$ documenting normal fertility in only $33 \%$ of males following spontaneous descent of bilateral maldescended testes after the age of ten.

Psychologically the optimum time for operating is the first 6 months of life. Separation from mother is most detrimental from 6 months to 4 years ${ }^{17}$, and ideally the mother should be with the child during his stay in hospital. There is some evidence that orchidopexy carried out before 2 years of age may reduce the risk of malignancy ${ }^{18}$, but not all agree that this is certain ${ }^{19}$.

In the light of available evidence there is a strong case to be made for operation around 2 years of age. The best hope for fertility depends on achieving the maximum potential of both testes. There is no good reason why surgery should be delayed despite the alleged technical difficulties of operating on young patients, as early surgery may prove to be important in reducing the risk of subsequent malignant change, and improving subsequent fertility. The presence of a hernia is generally accepted as an indication for early operation whatever the age.

In practice, too many children are already at school when first seen. In this survey $63 \%$ of the children underwent corrective surgery before the age of 5 years, a figure which compares favourably with the figure of $9 \%$ obtained by Bishop and Whitaker ${ }^{20}$. Only $8 \%$ of the operations were carried out before 2 years of age, and these were all performed within the last 18 months of this survey. This reflects the surgical practice of the consultant surgeons in post during this period.

The conclusion that can be drawn from this survey is that, although orchidopexies at this hospital are performed at ages that have been previously acceptable, there is a strong case for performing surgery much earlier. To this end it should become the normal practice for a child with maldescent to be referred for surgery as soon as the condition is diagnosed even in the neonatal period.

\section{REFERENCES}

1. BACKHouse $\mathrm{K}$ M. The gubernaculum testis Hunteriz testicular descent and maldescent. Ann $R$ Coll Surg Eng $\mathbb{Q}$ $1964 ; 35: 15-33$.

2. BACKHOUSE K M. The natural history of testicular desceng and maldescent. Proc R Soc Med 1966; 59: 357-60.

3. TAYLOR S. Maldescended Testis. Recent advances in. Surgery 10: 332-351. Churchill Livingstone, 1980.

4. Kiesewetter W B, Shull W $\mathrm{R}$ and Fetterman $\mathrm{G}$ Histological changes in the testis following anatomicall successful orchidopexy. J Pediatr Surg 1969; 4: 59-65.

5. HARding RaINS A J and Ritchie H D. Baily \& Love's Short Practice of Surgery 18th Ed. London. H. K. Lewis $\&$ Company Ltd. 1981.

6. JACKSON M, Pike M C and Gough M. Undescended testes - is surgery necessary? N Engl J Med Aug 21 1986; 315(8)? p 516-7.

7. SCORER C G. The descent of the testis. Arch Dis Chil $\overrightarrow{\&}$ 1964; 39: 605-9.

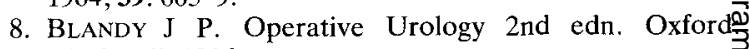
Blackwell, 1986.

9. LONDON $N$ J, JOSEPH $H T$ and JOHNSTONE J M $\frac{\dot{\prime}}{\dot{\omega}}$ Orchidopexy: the effect of changing patterns of referrat and treatment on outcome. BrJ Surg, Jul 1987; 74(7) p636-8.

10. Whit AKer R H. Management of the undescended testis $\$$ Br J Hosp Med, Jul 1970; 4: 25-37.

11. BREMHOLM RASMUSSEM T, INGERSLEV $H$ and HoSTRUPW Bilateral spontaneous descent of the testis after the agळुofn 10: subsequent effects on fertility. Br J Surg, Aug 190 74(8): $820-3$.

12. BianchI A. The undescended testis. Surgery, Apr 1(43): 1018-20.

13. FonkAlsRud $\mathrm{E} W$. The role and timing of surgery dof $\overrightarrow{0}$ cryptorchidism. Aust NZ J Surg, Oct 1984; 54(5): 431-

14. MENGEL W et al. Studies on cryptorchism: a compariso of histological findings in the germinative epithelium beres and after the second year of life. J. Pediatr Surg 1974, $445-450$.

15. HeCKer W C and Hienz H A. Cryptorchidism and fertilityô J Pediatr Surg 1967; 2: 513-17.

16. LAtTimer J K et al. The optimum time to operate for cryptorchidism. Paediatrics 1974; 53: 96-99.

17. SHAPIRO S R and Bodai B A. Current concepts of the undescended testis. Surg Gynaecol Obstet 1978; 147: 617 吾 25.

18. Fonkalsrud E $\mathrm{W}$ and Mengel W. The undescende $\underline{\underline{\Phi}}$ testis. Chicago; Year Medical Publications. 1981.

19. Pike M C, Chilvers, C and Peckham M J. Effect o̊ orchidopexy on risk of testicular cancer. Lancet May $3 \frac{\text { tे }}{2}$ 1986; 1(8492): $1246-8$.

20. BISHOP M C and WhITAKER R H 1979. Cryptorchidism: renewed plea. $\mathrm{Br} \mathrm{Med} J 1979 ; \mathbf{1}: 407-8$ 